\title{
Carbon Nanotubes as Affinity Probes for Peptides and Proteins in MALDI MS Analysis
}

\author{
Wei-Yu Chen, Lung-Shen Wang, Hsin-Tien Chiu, and Yu-Chie Chen \\ Department of Applied Chemistry, National Chiao Tung University, Hsinchu, Taiwan \\ Chi-Young Lee \\ Material Science Center and Department of Material Science and Engineering, National Tsing Hua \\ University, Hsinchu, Taiwan
}

\begin{abstract}
Recently, carbon nanotubes (CNTs) have been reported to be an effective MALDI matrix for small molecules (Anal. Chem. 2003, 75, 6191). In a somewhat related study, we have employed CNTs produced by using $\mathrm{NaH}$-treated anodic aluminum oxide $(\mathrm{Na} @ \mathrm{AAO})$ as a reactive template as the assisting matrix for MALDI analysis upon the addition of high concentrations of citrate buffer. Our results indicate that the mass range can be extended to ca. 12,000 Da and that alkali metal adducts of analytes are effectively reduced. Furthermore, we have employed citric acid-treated CNTs as affinity probes to selectively concentrate traces of analytes from aqueous solutions. High concentrations of salts and surfactants in the sample solutions are also tolerated. This approach is very suitable for the MALDI analysis of small proteins, peptides, and protein enzymatic digest products. (J Am Soc Mass Spectrom 2004, 15, 1629-1635) (c) 2004 American Society for Mass Spectrometry
\end{abstract}

$\mathrm{M}$ any research fields have benefited from Karas and Hillemkamp's invention of matrix-assisted laser desorption/ionization mass spectrometry (MALDI-MS) [1]. The MALDI analysis of proteins and peptides is applied routinely using organic matrices, such as sinapinic acid and 2,5-dihydroxybenzoic acid, but some problems arise when using organic compounds as the MALDI matrix. For example, analyte signals may be found only from specific spots and the high background signals of the matrix in the low-mass region may cause problems. Using inorganic species as the assisting materials in MALDI analysis is an alternative approach for avoiding the problems that arise in conventional MALDI analyses that use organic compounds as matrices. Tanaka and coworkers first introduced an inorganic matrix system, a fine cobalt powder $(30 \mathrm{~nm})$ mixed with glycerol, to assist laser desorption/ ionization of analytes [2], and several alternative inorganic matrix systems [3-14] have been developed since then. Sunner et al. were the first to demonstrate that carbon powder is an effective inorganic material that acts as an assisting material in a process that is also called surface-assisted laser desorption/ionization (SALDI) [3]. Unlike the nanoparticles used by Tanaka et al., micrometer-sized carbon powders, such as graphite or activated carbon, have been mixed with glycerol and

Published online September 25, 2004

Address reprint requests to Dr. Y.-C. Chen, Department of Applied Chemistry, National Chiao Tung University, 1001 Ta Hsueh Road, Hsinchu 300, Taiwan. E-mail: yuchie@mail.nctu.edu.tw used as the matrix system [3-8]. There are several advantages to using inorganic matrix systems for MALDI analysis, such as low matrix background signals and homogeneous sample deposition. Nevertheless, the presence of a liquid in the inorganic matrix system may limit this approach to high-throughput analyses because of the requirement for maintaining a high vacuum in the mass spectrometer. Alternatively, $\mathrm{C}_{60}$ and water-soluble fullerene derivatives have been employed alone as the assisting material in the MALDI analysis of proteins [15] and small molecules [16-18]. This fullerene approach, however, may suffer from some problems, such as low sensitivity and a low detectable mass range. Thus, only limited studies have been reported in which fullerenes have been used as MALDI matrices.

Recently, $\mathrm{Xu}$ et al. demonstrated that carbon nanotubes (CNTs) can act as an alternative carbon material for the MALDI analysis of small molecules [19] by employing the CNTs obtained from coal by arc discharging as the MALDI matrix. Sodium adductions of the analytes dominated the CNT MALDI mass spectra. Although this approach has advantages, including a low detection limit and low matrix background, the small range of observable molecules and the high abundance of sodiated analytes ions may limit the extent of this technique's applicable uses.

Since Iijima discovered the method for generating CNTs from carbon-arc discharging [20], many alternative methods for generating CNTs have been proposed [21-26]. Recently, we developed a straightforward 
method for producing CNTs that uses Na@AAO as a reactive template [26]. These types of CNTs have large diameters (ca. $250 \mathrm{~nm}$ ) and long tube lengths (ca. $60 \mu \mathrm{m}$ ) and can be dispersed very well in solution. By employing this type of CNT as the MALDI matrix, we have obtained very promising results for the analysis of proteins and peptides. We have found that adding a citrate buffer provides an extra proton source and also reduces the intensities of sodium adductions of analytes during MALDI analysis [27]. The alkali cation adducts are effectively reduced, which leads to protonated analyte ions being the dominant ions in the CNT MALDI mass spectra.

It has been demonstrated that the surfaces of CNTs can be easily modified in numerous ways by either covalent or noncovalent functionalization [28-35]. For instance, Jiang and Gao have proposed a method for modifying CNT surfaces by immersing them in a citric acid solution, which results in the surfaces of the CNTs becoming anionic [36]. We have applied such citric acid-treated CNTs as affinity probes for selectively concentrating oppositely charged species from aqueous solutions through electrostatic interactions. After the specific target species are attracted to the surface of the CNTs through these electrostatic interactions, the CNTs that are conjugated with the target species can then be introduced directly into a mass spectrometer for MALDI analysis without the necessity of adding any extra MALDI matrix. Because amphiprotic species, such as peptides and proteins, have unique isoelectric points $(\mathrm{pI})$, when the $\mathrm{pH}$ of a solution of a protein sample is below the value of $\mathrm{pI}$ of that protein, those protein molecules carry net positive charge. The positively charged proteins can be trapped onto the surfaces of the citric acid-treated CNTs. By varying the values of $\mathrm{pH}$ of the sample solution, specific target proteins or peptides can be concentrated selectively on the surface of the citric acid-treated CNTs. We have also employed this affinity approach for the analysis of proteomic samples. In solution at $\mathrm{pH} 4$, a high proportion of digest peptide residues carry positive charge and, therefore, they can become attached and concentrated onto the negatively charged surfaces of CNTs through ionic interactions. Using this approach, our results demonstrate that low concentrations of protein enzymatic digest products can be concentrated and identified through the combination of MALDI analysis and protein database searches.

\section{Experimental}

Reagents

Ammonium hydroxide and sodium hydroxide were purchased from J. T. Baker (Phillipsburg, NJ). Methanol was obtained from Tedia (Fairfield, OH). Melittin, tetradecyltrimethylammonium bromide, and dodecyltrimethylammonium bromide were obtained from Fluka (Buchs, Switzerland). Citric acid, cytochrome $c$ (horse heart), and trypsin were obtained from Sigma (St. Louis,
MO). Ammonium hydrogen carbonate, diammonium hydrogen citrate, and triammonium phosphate were obtained from Riedel-de Haën (Seelze, Germany). Ethanol was obtained from Showa (Tokyo, Japan). Sodium hydride, $\alpha$-cyano-4-hydroxycinnamic acid (CHCA), and hexachlorobenzene were obtained from Aldrich (Milwaukee, WI).

\section{Preparation of CNTs}

The detailed methods for generating the CNTs are described elsewhere [26]. Briefly, $\mathrm{NaH}$ was placed above a piece of anodic aluminum oxide (AAO; Whatman Anodisk 13; pore diameter: $200 \mathrm{~nm}$; thickness: 60 $\mu \mathrm{m})$ and heated inside a tube furnace at $623 \mathrm{~K}$ under 1 $\mathrm{atm}$ of Ar (flow rate: $30 \mathrm{sccm}$ ) for $1 \mathrm{~h}$ to generate an air-sensitive silvery plate (Na@AAO). The piece of $\mathrm{Na} @ \mathrm{AAO}$ was further reacted with the vapor of hexachlorobenzene (toxicity: $\mathrm{LD}_{50}$ oral, mouse $=4 \mathrm{~g} / \mathrm{kg}$, vaporized at $373 \mathrm{~K}$ ) at $623 \mathrm{~K}$ under $1 \mathrm{~atm}$ of Ar flow for $20 \mathrm{~h}$ in a tube furnace to generate a black product. A black solid disk having the original shape of the AAO plate was obtained. $\mathrm{NaCl}$, the by-product, was vaporized during high-temperature treatment (1073 K) under vacuum. Subsequently, the AAO was removed by soaking the CNT@AAO in 48\% HF solution at room temperature for $9 \mathrm{~h}$. The sample was further washed with hot water and then air-dried at $373 \mathrm{~K}$ to remove impurities.

\section{Sample Preparation for Direct CNT MALDI Analysis}

CNTs (3 mg) were suspended in a $1 \mathrm{~mL}$ of ethanol/ citrate buffer (4/1, vol/vol) containing $50 \mathrm{mM}$ diammonium hydrogen citrate and $50 \mathrm{mM}$ citric acid and then sonicated for $3 \mathrm{~min}$ to disperse the CNTs well in the solution. The two-layer sample preparation method was employed for MALDI samples. A CNT solution $(0.2 \mu \mathrm{L})$ was first applied on an AnchorChip (Bruker Daltonics, Germany) sample target. After the volatile solution evaporated, a solution $(0.2 \mu \mathrm{L})$ of the sample dissolved in citric acid (50 mM) was applied on top of the CNT layer. After the volatile solvent evaporated, the sample target was sent into a mass spectrometer for MALDI analysis.

\section{Preparation of Cytochrome C Tryptic Digest}

Cytochrome $c$ tryptic digestion was carried out at $38^{\circ} \mathrm{C}$ for $24 \mathrm{~h}$ at a protein-to-enzyme weight ratio of 41:1. Particularly, two solutions of cytochrome $c\left(10^{-5} \mathrm{M}\right.$ and $10^{-6} \mathrm{M} ; 0.1 \mathrm{~mL}$ ) prepared in an $\mathrm{NH}_{4} \mathrm{HCO}_{3}$ buffer solution $(25 \mathrm{mM})$ were reacted with two solutions of trypsin $(0.1$ and $0.01 \mathrm{mg} / \mathrm{mL}$, respectively; $3 \mu \mathrm{L}$ ). The digest product was diluted ten times using either citrate buffer $(\mathrm{pH} 4)$ or digest buffer $(\mathrm{pH}$ 7.9) to adjust the 
values of $\mathrm{pH}$ before performing the $\mathrm{CNT}$ extraction experiments.

\section{Using CNTs as Affinity Probes}

The experiments in which we used CNTs as affinity probes for trace analytes in aqueous solutions were carried out at different values of $\mathrm{pH}$ or by using different aqueous solutions containing high concentrations of surfactants. Citric acid was added to a diammonium citrate solution (100 $\mathrm{mM}$ ) to adjust its value of $\mathrm{pH}$ to 4 , while ammonia was added to a triammonium phosphate solution $(100 \mathrm{mM})$ to adjust its value of $\mathrm{pH}$ to $10.1 \mathrm{M} \mathrm{NaOH}$ was added to the triammonium phosphate solution $(100 \mathrm{mM})$ to obtain a solution at $\mathrm{pH} 12$.

A CNT solution $(3 \mathrm{mg} / \mathrm{mL})$ was prepared in a solution of ethanol/citric acid (4:1, vol/vol; $100 \mathrm{mM}$ ) and sonicated for $5 \mathrm{~min}$ to disperse the CNTs well in the solution as the citric acid units became attached onto their surfaces. The attachment of citric acid onto the surfaces of CNTs was confirmed by using infrared spectroscopy. An absorption band at $1721 \mathrm{~cm}^{-1}$ corresponding to a $\mathrm{C}-\mathrm{O}$ stretching vibration was obtained in the IR absorption spectrum of the citric acid-treated CNTs. For the extraction experiments, a sample of the CNT solution $(1 \mu \mathrm{L})$ was added to a sample solution $(49 \mu \mathrm{L})$ under a variety of values of $\mathrm{pH}$ and buffer conditions. The whole sample solution was gently vortexed for $1 \mathrm{~h}$. After vortexing, the solution was centrifuged at 10,000 rpm and the supernatant was removed by pipette. Subsequently, a buffer solution ( 50 or $20 \mu \mathrm{L}$, the same buffer as that used in the sample solution) was added to wash out any unwanted impurities from the CNTs that remained in the vial. Again, the supernatant solution was removed after centrifugation. The remaining CNT was resuspended in a citric acid solution (100 mM, $0.3 \mu \mathrm{L}$ ) and then a portion of this suspended solution $(0.3 \mu \mathrm{L})$ was applied on an AnchorChip target for MALDI analysis.

To demonstrate that CNTs could effectively select and concentrate target biomolecules from a sample solution containing large quantities of interfering species, the extraction experiments were performed by adding a CNT solution ( $3 \mathrm{mg} / \mathrm{mL}, 1 \mu \mathrm{L})$ to a sample solution $(19 \mu \mathrm{L})$ containing a high concentration of surfactants. After gently vortexing for $1 \mathrm{~h}$, the solution was centrifuged at 10,000 rpm and the supernatant solution was removed by pipette. Subsequently, deionized water (DI) water $(3 \times 50 \mu \mathrm{L})$ was added to the CNTs remaining in the vial to wash out any unwanted impurities. The supernatant solution was then removed after centrifugation. Subsequently, the remaining CNT was resuspended in a citric acid solution $(100 \mathrm{mM}, 1$ $\mu \mathrm{L})$. A portion of this suspended solution $(0.3 \mu \mathrm{L})$ was applied onto an AnchorChip target for MALDI analysis.

\section{Instrumentation}

All mass spectra were obtained using a Biflex III (Bruker Daltonics, Germany) time-of-flight mass spectrometer. The mass spectrometer was equipped with a $337-\mathrm{nm}$ nitrogen laser and a $1.25-\mathrm{m}$ flight tube. The reflectron mode was used for the MALDI analysis of the digest samples. In this study, we used AnchorChip sample targets that have the capacity to load 384 samples simultaneously. When depositing the CNT sample to the AnchorChip target, the sample aggregated on the hydrophilic center of the well $(600 \mu \mathrm{m})$. The accelerating voltage was set to $19 \mathrm{kV}$. The CNTs on carbon tapes were coated with a thin layer of gold (ca. $5 \mathrm{~nm}$ ) and characterized by SEM (JEOL JSM-6330F at $15 \mathrm{kV})$. The IR spectrum was obtained using a PerkinElmer FTIR spectrometer.

\section{Results and Discussion}

Figure 1 displays the SEM images of the CNTs used in this study. The images indicate that the CNTs have diameters of ca. $250 \mathrm{~nm}$ and tube lengths of ca. $60 \mu \mathrm{m}$. We employed the CNTs alone as the assisting matrix during MALDI analysis. Figure 2 presents the CNT
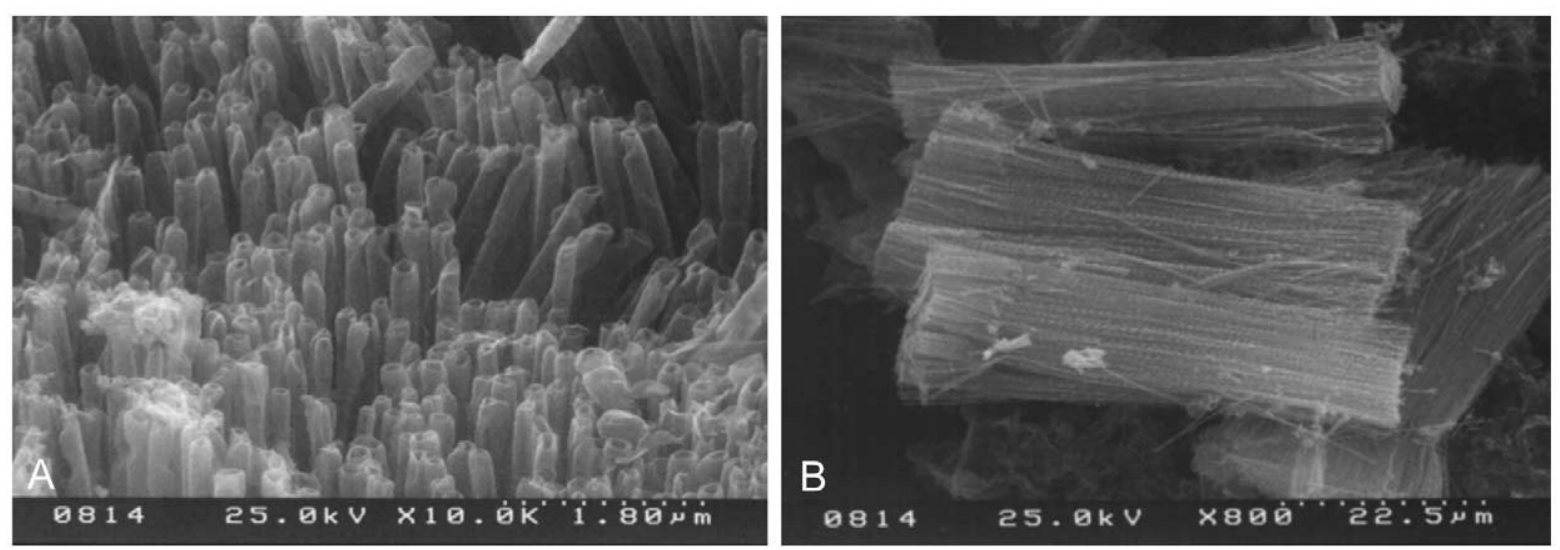

Figure 1. SEM images of CNTs. The images indicate that the CNTs have large diameters (ca. $250 \mathrm{~nm}$ ) and long tube lengths (ca. $60 \mu \mathrm{m}$ ). 


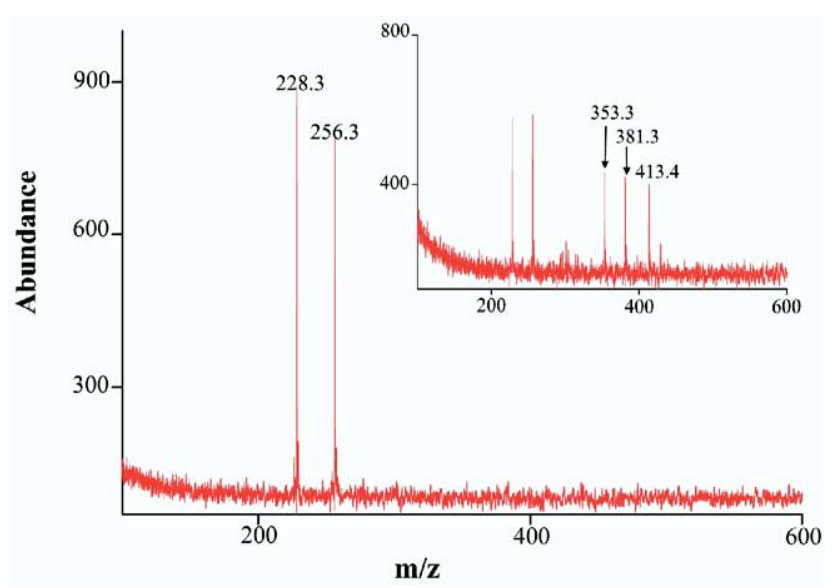

Figure 2. CNT MALDI mass spectrum of a mixture of tetradecyltrimethylammonium bromide $(48.6 \mathrm{fmol})$ and dodecyltrimethylammonium bromide $(29.7 \mathrm{fmol})$. The inset presents the CNT MALDI mass spectrum of a mixture of these salts at 4.9 and $3.0 \mathrm{fmol}$, respectively.

MALDI mass spectrum of the mixture of tetradecyltrimethylammonium bromide $\left(\mathrm{C}^{+} 4^{+}, 48.6 \mathrm{fmol}\right)$ and dodecyltrimethylammonium bromide $\left(\mathrm{C}^{2} 2^{+}, 29.7 \mathrm{fmol}\right)$. The cationic ions of $\mathrm{C}_{14}{ }^{+}$and $\mathrm{C} 12^{+}$appear at $\mathrm{m} / \mathrm{z} 228.3$ and 256.3, respectively. We observed no background ions in the mass spectrum, but matrix background ions at $\mathrm{m} / \mathrm{z} 353.3,381.3$, and 413.4 may arise in the mass spectra when a higher laser power is required to desorb lower amounts of analytes (see the mass spectrum presented as the inset to Figure 2).

The largest molecule that we observed in the mass spectrum when using the CNTs as the MALDI matrix was insulin ( $\mathrm{MW}=5733$; Figure 3a). The observable mass range is larger than that reported in a previous study [19] (ca. $1200 \mathrm{Da}$ ) in which CNTs generated by arc-discharging were used as the MALDI matrix, but the mass quality is still poor because of the presence of large quantities of alkali cation adducts of analytes.

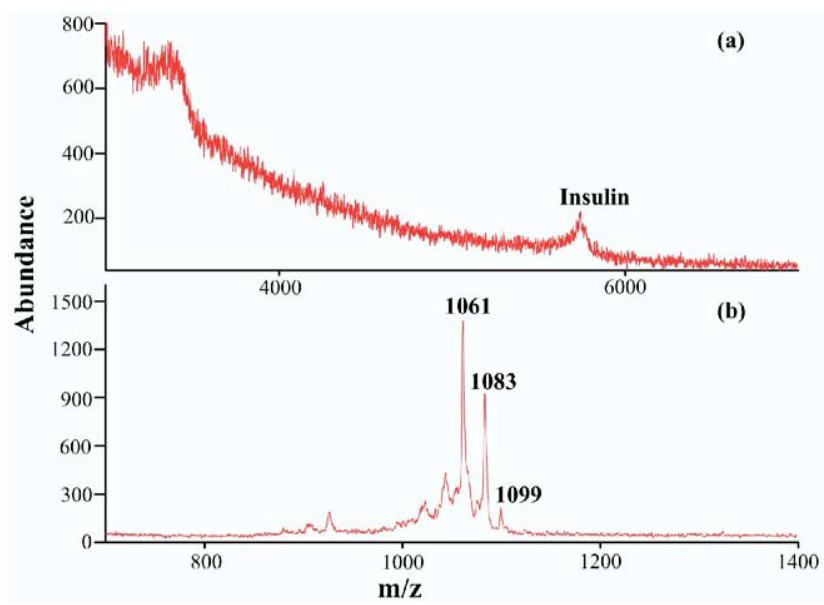

Figure 3. CNT MALDI mass spectra of (a) insulin (35 pmol) and (b) bradykinin $(18.9 \mathrm{pmol})$. The CNTs were used alone as the MALDI matrix.
Figure $3 \mathrm{~b}$ displays the CNT MALDI mass spectrum of bradykinin. The peaks at $\mathrm{m} / \mathrm{z}$ 1099, 1083, and 1061 correspond to the $\mathrm{MK}^{+}, \mathrm{MNa}^{+}$, and $\mathrm{MH}^{+}$ions, respectively, of bradykinin.

Reducing the intensities of the alkali cation adductions should improve both the mass spectral quality and sensitivity. Thus, to achieve these goals, we added a high concentration of citric acid into the CNT system. Figure 4 presents the CNT MALDI mass spectra of three biomolecules dissolved in citric acid solution $(50 \mathrm{mM})$; the protonated pseudomolecular analyte ions are now the dominant ions in these mass spectra. Clearly, the alkali ion adducts of the analytes have been reduced effectively. Figure 4a displays the intense $\mathrm{MH}^{+}$peak of insulin at $m / z 5734$; the mass spectral quality is dramatically improved when compared with the result presented in Figure 3a. Figure $4 \mathrm{~b}$ displays the CNT MALDI mass spectrum of cytochrome $c$, which is the largest molecule we have detected so far when using this approach. Both the $\mathrm{MH}^{+}$and $\mathrm{MH}_{2}{ }^{2+}$ ions of cytochrome $c$ are observed, at $m / z 12,361$ and 6181, respectively, in the same mass spectrum. An expanded mass range around the cytochrome $c$ ion signal is presented in the inset to Figure $4 \mathrm{~b}$. The lower-mass trailing edge indicates a substantial degree of metastable decay at this mass. Figure 4c presents the CNT MALDI mass spectrum of bradykinin at the lowest detection limit (9.4 fmol) we have achieved when using this approach. The results demonstrate that the presence of citric acid dramatically improves both the mass spectral quality and sensitivity, and it eliminates the presence of the alkali ion adductions. Citric acid does not absorb the light of the UV laser used in a MALDI mass spectrom-

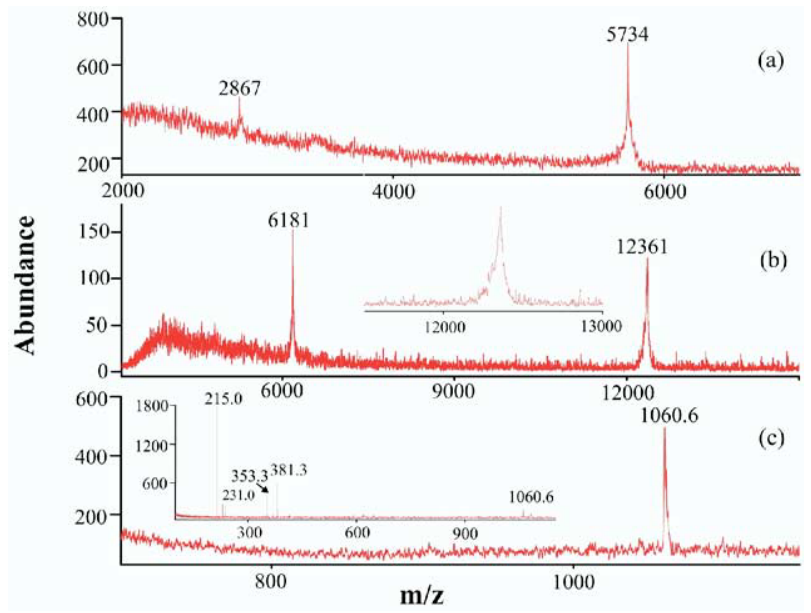

Figure 4. CNT MALDI mass spectra of (a) insulin (87 fmol), (b) cytochrome $c(800 \mathrm{fmol})$, and $(\mathrm{c})$ bradykinin $(9.4 \mathrm{fmol})$. The inset mass spectrum in (b) displays the expanded mass range around the cytochrome $c$ ion signal, while the inset in (c) displays the CNT MALDI mass spectrum of bradykinin $(940 \mathrm{fmol}$ ) obtained without suppressing the low-mass ions. The CNTs were suspended in an ethanol/citrate $(4: 1, \mathrm{vol} / \mathrm{vol})$ buffer solution. The citrate buffer consists of diammonium hydrogen citrate $(50 \mathrm{mM})$ and citric acid $(50 \mathrm{mM})$. The analytes were dissolved in a citric acid solution (50 $\mathrm{mM})$. 
eter, but it does provide an extra proton source for protonation of the analytes. Unfortunately, the presence of citric acid in the sample can suppress the analyte signal if low-mass ions were not suppressed (see the mass spectrum presented as the inset to Figure 4c). The sodium and potassium adducts of citric acid appear at $\mathrm{m} / \mathrm{z} 215.0$ and 231.0, respectively, and the background ions generated from the CNTs at $\mathrm{m} / \mathrm{z} 353.3$ and 381.3 have much higher abundance than do those of the protonated bradykinin ions (940 fmol). Thus, the lowmass ions generally were suppressed when performing the CNT MALDI analysis.

Citric acid-treated CNTs have the potential to trap very low concentrations of oppositely charged analytes from sample solutions through electrostatic interactions. To demonstrate the feasibility of this approach, we used a very low concentration of insulin as the extraction solution. The value of the $\mathrm{pI}$ of insulin is 5.3 and, thus, it has a net positive charge in solution at $\mathrm{pH}$ 4. Figure 5a displays the CNT MALDI mass spectrum of insulin obtained after citric acid-treated CNTs were used as affinity probes to trap a trace amount of insulin $\left(10^{-8} \mathrm{M}\right)$ from a solution $(50 \mu \mathrm{L})$ at $\mathrm{pH}$ 4. The protonated pseudomolecular ion of insulin $\left(\mathrm{MH}^{+}\right)$at $m / z 5734$ dominates the mass spectrum. The insulin ion peak was not observed, however, in the CNT MALDI mass spectrum when the extraction experiment was carried out using a sample solution at a $\mathrm{pH} 10$ (Figure 5b). We believe that this result arises because insulin molecules carry net negative charge at $\mathrm{pH} 10$, which results in their being unsuitable for trapping on the negatively charged surfaces of the CNTs.

Although the matrix preparation steps for this CNT matrix system do not require any co-crystallization process, as is required in conventional MALDI analysis, the presence of large quantities of salts or surfactants present in the samples can degrade the mass spectral quality. To

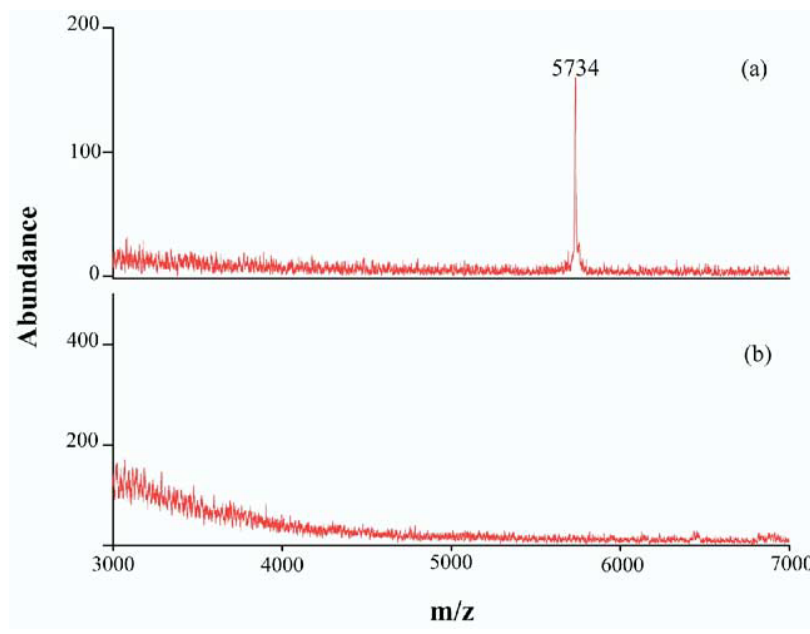

Figure 5. CNT MALDI mass spectra of insulin obtained using citric acid-treated CNTs as affinity probes to trap insulin from sample solutions $(50 \mu \mathrm{L})$ containing $10^{-8} \mathrm{M}$ insulin at (a) $\mathrm{pH} 4$ and (b) $\mathrm{pH} 10$.

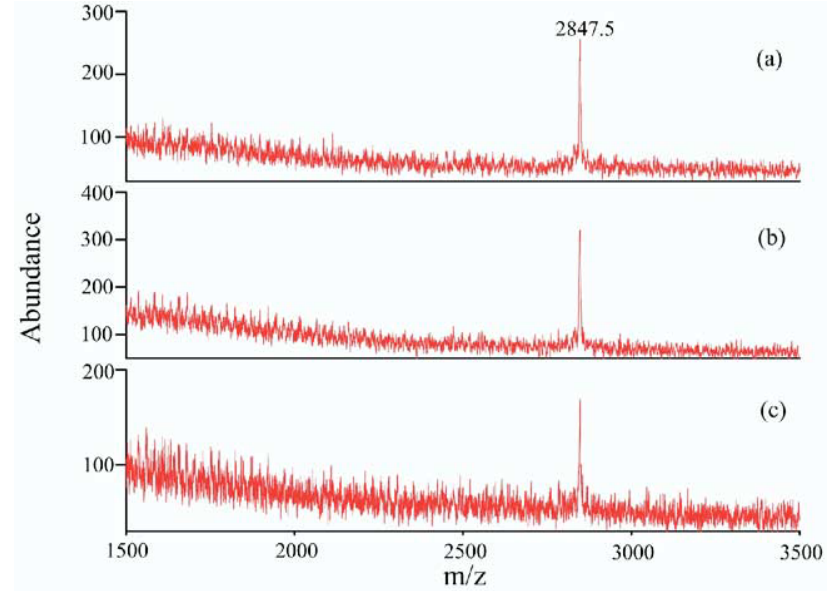

Figure 6. CNT MALDI mass spectra of a melittin solution $(4 \times$ $10^{-8} \mathrm{M}$ ) containing (a) $19.2 \%$ Triton X-100 and (b) $7.68 \mathrm{M}$ urea. (c) CNT MALDI mass spectra of a melittin solution $\left(4 \times 10^{-7} \mathrm{M}\right)$ containing $0.096 \%$ SDS. These spectra were obtained after using citric acid-treated CNTs as affinity probes to trap melittin from a sample solution $(20 \mu \mathrm{L})$.

demonstrate that CNTs can act as selective and concentrating probes for target species in sample solutions, we must reveal that the CNTs can exclude any interference from surfactants or salts throughout the extraction steps. Thus, we performed the extraction experiments using several sample solutions that contain high quantities of potentially interfering species. Figure $6 a$ and $b$ display the CNT MALDI mass spectra of melittin obtained after using the citric acid-treated CNTs as affinity probes to trap traces of melittin from sample solutions $\left(4 \times 10^{-8} \mathrm{M}, 20\right.$ $\mu \mathrm{L}$ ) containing $19.2 \%$ Triton $\mathrm{X}-100$ and $7.68 \mathrm{M}$ urea, respectively. The protonated pseudomolecular ion of melittin at $\mathrm{m} / \mathrm{z} 2847.5$ dominates both of these mass spectra. No analyte peak was observed, however, in the

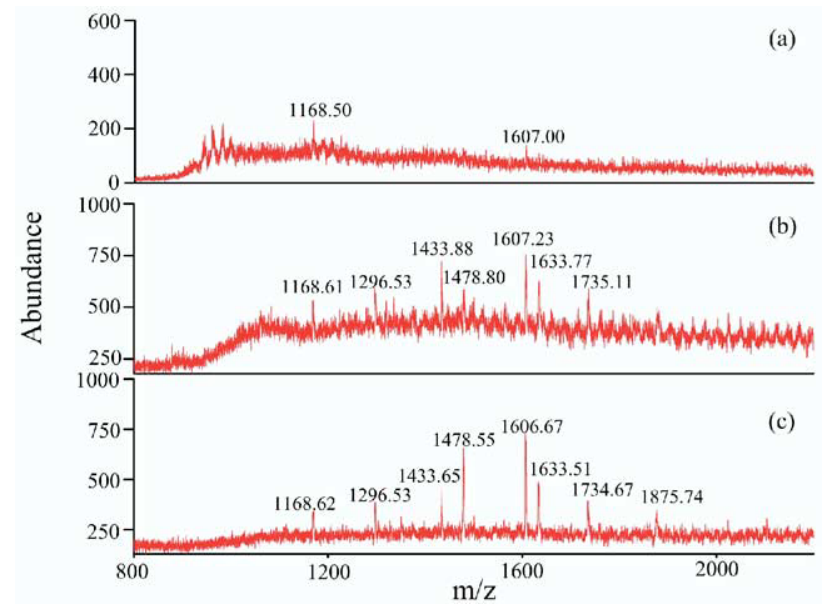

Figure 7. (a) MALDI mass spectrum of a cytochrome $c\left(2 \times 10^{-8} \mathrm{M}\right.$, $0.3 \mu \mathrm{L})$ tryptic digest product. CHCA was used as the matrix. (b, c) CNT MALDI mass spectra of a cytochrome $c\left(2 \times 10^{-8} \mathrm{M}\right)$ tryptic digest product obtained after using citric acid-treated CNTs as affinity probes to trap peptide residues from a cytochrome $c$ tryptic digest sample solution ( $50 \mu \mathrm{L})$ at $\mathrm{pH} 7.9$ and 4, respectively. 
Table 1. Ions observed in the CNT MALDI mass spectrum of cytochrome $c$ tryptic digest and a comparison with the output of the NCBI database

\begin{tabular}{lcclr}
\hline Observed $\mathrm{m} / \mathrm{z}$ & Start-End sequence & Miss $^{\mathrm{a}}$ & Peptide sequence & Theoretical pl $^{\mathrm{b}}$ \\
\hline \hline 1168.62 & $28-38$ & 0 & TGPNLHGLFGR & 9.44 \\
1296.53 & $28-39$ & 1 & TGPNLHGLFGR & 11.00 \\
1433.65 & $26-38$ & 1 & HKTGPNLHGLFG & 11.00 \\
1478.55 & $89-100$ & 2 & TEREDLIAYLKK & 5.85 \\
1606.67 & $88-100$ & 3 & KTEREDLIAYLKK & 8.43 \\
1633.51 & $9-22$ & 1 & IFVOKCAOCHTVEK & 8.06 \\
1734.67 & $87-100$ & 4 & KKTEREDLIAYLKK & 9.4 \\
1875.74 & $9-25$ & 2 & IFVOKCAOCHTVEKGGK & 8.86 \\
\hline
\end{tabular}

${ }^{a}$ Number of missed cleavages.

bTheoretical values of pl were obtained using a computational tool located at http://tw.expasy.org.

CNT MALDI mass spectra obtained prior to the extraction treatment (results not shown). Figure $6 \mathrm{c}$ presents the CNT MALDI mass spectrum of melittin obtained after employing the citric acid-treated CNTs as affinity probes to trap trace melittin from a melittin sample solution $\left(4 \times 10^{-7} \mathrm{M}\right.$, $20 \mu \mathrm{L}$ ) containing $0.096 \%$ SDS. The $\mathrm{MH}^{+}$ion of melittin dominates this mass spectrum also. These results indicate that citric acid-treated CNTs can be employed effectively as selective probes that exclude large quantities of the typical interfering species that might be present in sample solutions.

We have demonstrated that this CNT MALDI approach can be effective for analyzing molecules with molecular weights in the range 1000-12,000 Da. Furthermore, the CNTs can be used directly as concentrating probes for trace analytes. Thus, this technique should be suitable for the analysis for enzymatic digest products, which generally have very low concentrations and various molecular sizes distributed within the detectable mass range. To demonstrate the feasibility of this application, we employed a cytochrome $c\left(2 \times 10^{-8} \mathrm{M}, 50 \mu \mathrm{L}\right)$ tryptic digest product as the extraction sample. The extraction experiments were performed using solutions at two different values of $\mathrm{pH}$ : one at $\mathrm{pH} 7.9$ and the other at $\mathrm{pH} 4$. Figure $7 \mathrm{a}$ presents the MALDI mass spectrum of the cytochrome $c\left(2 \times 10^{-8} \mathrm{M}\right)$ tryptic digest product prior to extraction. Only very weak peaks at $m / z 1168.50$ and 1607.00 are observed in the mass spectrum. Figure $7 \mathrm{~b}$ presents the CNT MALDI mass spectrum of the cytochrome $c$ tryptic digest product obtained after using citric acid-treated CNTs as affinity probes to selectively concentrate peptides from a digest product sample ( $\mathrm{pH} 7.9)$. Several peaks at $m / z 1168.61,1296.53,1433.88,1478.80$, $1606.67,1633.77$, and 1735.11 are present in this CNT MALDI mass spectrum. A very weak peak at $\mathrm{m} / \mathrm{z} 1478.80$ (89-100) was observed, even though the theoretical value of the $\mathrm{pI}$ of this peptide residue is 5.85. Presumably, this ion might be the fragment formed upon losing a lysine unit from the peptide residue at $m / z$ 1607.23 (88-100). When the extraction experiment was performed using the sample solution at $\mathrm{pH} 4$, the peaks at $m / z 1168.62,1296.53$, 1433.65, 1478.55, 1606.67, 1633.51, 1734.67, and 1875.74, which correspond to the peptide residues of cytochrome $c$, appear with higher intensity in the CNT MALDI mass spectrum (Figure 7c) than they did in Figure 7b. In particular, the intensity of peptide residue 89-100 at $\mathrm{m} / \mathrm{z}$ 1478.83 is greatly enhanced when extracted at $\mathrm{pH} 4$. Through protein database searches, we matched each peak to peptide residues of cytochrome $c$ and, furthermore, we obtained a probability-based Mowse score of 122. Table 1 lists the detailed amino acid sequences and the corresponding theoretical values of $\mathrm{pI}$ for each peptide residue. All of the $\mathrm{pI}$ values of these peptides residues are $>4$, which means that each one bears a net positive charge in solution at $\mathrm{pH} 4$. Therefore, these peptide residues are attracted selectively to the negatively charged surfaces of the CNTs. The results again demonstrate the usefulness of employing the critic acid-treated CNTs as effective affinity probes for traces of cationically charged species.

\section{Conclusions}

We have demonstrated that CNTs generated from a reactive AAO template act as a suitable MALDI matrix for the analysis of peptides and small proteins. Citric buffer was added into the CNT matrix system to reduce the intensities of alkali cation adducts and also to extend the detectable mass range. Additionally, the citric acid-treated CNTs can be used as selective and concentrating probes to effectively trap cationically charged target species from sample solutions. This CNT MALDI approach is especially feasible for the analysis for very low concentrations of protein enzymatic digest products.

\section{Acknowledgments}

The authors thank the National Science Council of Taiwan for financial support of this research.

\section{References}

1. Karas, M.; Hillenkamp, F. Anal. Chem. 1988, 60, 2299-2301.

2. Tanaka, M.; Waki, H.; Ido, Y.; Akita, S.; Yoshida, T. Rapid Commun. Mass Spectrom. 1988, 2, 151-153.

3. Sunner, J.; Dratz, E.; Chen, Y.-C. Anal. Chem. 1995, 67, 4335-4342.

4. Dale, M. J.; Knochenumss, R.; Zenobi, R. Anal. Chem. 1996, 68, 3321-3329.

5. Kraft, P.; Alimipiev, S.; Drats, E.; Sunner, J. J. Am. Soc. Mass Spectrom. 1998, 9, 912-924. 
6. Park, K.-H.; Kim, H.-J. Rapid Commun. Mass Spectrom. 2001, 15, 1494-1499.

7. Chen, Y.-C.; Tsai, M.-F. J. Mass Spectrom. 2000, 35, 1278-1284.

8. Wu, J.-Y.; Chen, Y.-C. J. Mass Spectrom. 2002, 37, 85-90.

9. Wei, J.; Buriak, J. M.; Siuzdak, G. Nature 1999, 399, 243-246.

10. Kruse, R. A.; Li, X.; Bohn, P. W.; Sweedler, J. V. Anal. Chem. 2001, 73, 3639-3645.

11. Shen, Z.; Thomas, J. J.; Averbuj, C.; Broo, K. M.; Engelhard, M.; Crowell, J. E.; Finn, M. G.; Siuzdak, G. Anal. Chem. 2001, 73, 612-619.

12. Bhattacharya, S.; Raiford, T. J.; Murray, K. K. Anal. Chem. 2002, 74, 2228-2231.

13. Cuiffi, J. D.; Hayes, D. J.; Fonasj, S. J.; Brown, K. N.; Jones, A. D. Anal. Chem. 2001, 73, 1292-1295.

14. Rechthaler, J.; Allmaier, G. Rapid Commun. Mass Spectrom. 2002, 16, 899-902.

15. Michalak, L.; Fisher, K. J.; Alderdice, D. S.; Jardine, D. R.; Willett, G. D. Org. Mass Spectrom. 1994, 29, 512-515.

16. Hopwood, F. G.; Michalak, L.; Alderdice, D. S.; Fisher, K. J.; Willett, G. D. Rapid Commun. Mass Spectrom. 1994, 8, 881-885.

17. Huang, J.-P.; Yuan, C.-H.; Shiea, J.; Chen, Y.-C. J. Anal. Toxicol. 1999, 23, 337-342.

18. Shiea, J.; Huang, J.-P.; Teng, C.-F.; Jeng, J.; Wang, L. Y.; Chiang, L. Y. Anal. Chem. 2003, 75, 3587-3595.

19. Xu, S.; Li, Y.; Zou, H.; Qiz, J.; Guo, Z.; Guo, B. Anal. Chem. 2003, 75, 6191-6195.

20. Iijima, S. Nature 1991, 354, 56-58.

21. Ajayan, P. M.; Iijima, S. Nature 1992, 358, 23.

22. Colbert, D.; Smalley, R. E. Carbon 1995, 33, 921-924.

23. Journet, C.; Maser, W. K.; Bernier, P.; Losieau, A.; Delachapell, M. L.; Lefrant, S.; Deniard, P.; Lee, R.; Fischer, J. E. Nature 1997, $388,756-758$.
24. Thess, A.; Lee, R.; Nikolaev, P.; Dai, H. J.; Petit, P.; Robert, J.; Xu, C. H.; Lee, Y. H.; Kim, S. G.; Rinzler, A. G.; Colbert, D. T.; Scuseria, G. E.; Tomanek, D.; Fischer, J. E.; Smalley, R. E. Science 1996, 273, 483-487.

25. Hafner, J. H.; Bronikowski, M. J.; Azamian, B. R.; Nikolaev, P.; Rinzler, A. G.; Colbert, D. T.; Smith, K. A.; Smalley, R. E. Chem. Phys. Lett. 1998, 296, 195-202.

26. Wang, L.-S.; Lee, C.-Y.; Chiu, H.-T. Chem. Commun. 2003, 15, 1964-1965.

27. Chen, C.-T.; Chen, Y.-C. Rapid Commun. Mass Spectrom. 2004, 18, 1956-1964.

28. Balavoine, F.; Schultz, P.; Richard, C.; Mallouh, V.; Ebbesen, T. W.; Mioskowski, C. Angew. Chem. Int. Ed. 1999, 38, 19121915.

29. Erlanger, B. F.; Chen, B.-X.; Zhu, M.; Brus, L. Nano Lett. 2001, 1, 465-467.

30. Chen, R. J.; Zhang, Y.; Wang, D.; Dai, H. J. Am. Chem. Soc. 2001, $123,3838-3839$.

31. Shim, M.; Kam, N. W. S.; Chen, R. J.; Li, Y.; Dai, H. Nano Lett. 2002, 2, 285-288.

32. Chen, R. J.; Bangsaruntip, S.; Drouvalakis, K. A.; Kam, N. W. S.; Shim, M.; Li, Y.; Kim, W.; Utz, P. J.; Dai, H. Proc. Natl. Acad. Sci. U.S.A. 2003, 100, 4984-4989.

33. Besteman, K.; Lee, J.-O; Wiertz, F. G. M.; Heering H. A.; Dekker, C. Nano Lett. 2003, 3, 727-730.

34. Star, A.; Gabriel J.-C. P; Bradley, K.; Crüner, G. Nano Lett. 2003, 3, 459-463.

35. Chen, R. J.; Choi, H. C.; Bangsaruntip, S.; Yenilmez, E.; Tang, X.; Wang, Q.; Chang, Y.-L; Dai, H. J. Am. Chem. Soc. 2004, 126, 1563-1568.

36. Jiang, L.; Gao, L. Carbon 2003, 41, 2923-2929. 